\title{
Technology Advancement in Vedic Psychology
}

\author{
Vani Nayal, Dr. Madhu Lata Nayal
}

\begin{abstract}
This paper discuss the overlooked aspects regarding the underlying advancement in technology in vedic psychology. Vedic psychology teaches how to control your mind as sometimes it can act as a friend or an enemy. The control of the mind is a major point to discuss about. The culprit for many modern day diseases, which are too often erroneously blamed on external circumstances, is lack in control. So as the technology have grown with a fast pace the problems related to anxiety, stress, anger, fears etc can be solved with the help of some technical applications. They help us to be calm, focused and we can meditate at anytime, anywhere. So in this paper researcher will discuss about how the applications that came as a advanced solutions to the problems that are been majorly faced by everyone in their day to day lives.
\end{abstract}

Index Terms-Technology advancement, Upanishads, Vedic psychology, Yoga

\section{INTRODUCTION}

Vedic psychology is related to the soul. The soul makes matter function. Vedic psychology deals with the question that how the soul perceives this world.

Vedic psychology is a new field of science created by Satyanarayana Dasa[1], that is studying and teaching from the ancient vedic scriptures for about four decades, it is the most profound and thorough body of knowledge on all aspects of the human mind and soul. Vedic psychology's dynamic approach blends a framework of ultimate truths shared by self-realized beings, with modern day psychotherapy, yoga, and ayurveda techniques. It deals with sharpening self-awareness, selfobservation and introspection skills. It is an internal journey towards the truth of introspection. It also gives practical approach on how to stay calm in the present moment, and how to avoid acting impulsively upon the moody and convincing mind's likes and dislikes, pleasures or pains. The study of the human mind is useful for every person, as it helps in personal relationships,

\footnotetext{
Manuscript revised October 15, 2019 and published on November 10, 2019

Vani Nayal, B.Tech Electronics and communication student, Birla Institute of Applied Sciences, Bhimtal, India.

Dr Madhu Lata Nayal, Dept of Psychology, SSJ Campus, Kumao University, Almora, India.
}

work relationships, and in cultivating a loving, compassionate relationship with ourselves. Vedic psychology helps us to understand the parts of the mind and how they behave, just like understanding the parts of a machine before we use it. Knowing this enables us to detach from our mind, so we can gain control in it, ultimately liberating us to become free and set us in a place of permanent peace.

\section{CONCEPT OF VEDAS}

The Vedas are knowledge texts originated in ancient India. It is written in Vedic Sanskrit, the text constitute the oldest layer of Sanskrit literature and the oldest scriptures of Hinduism Vedas are called "sruti" (what is heard) literature, distinguishing them from other religious texts, which are called "smrti"(what is remembered)[2].

There are four Vedas:

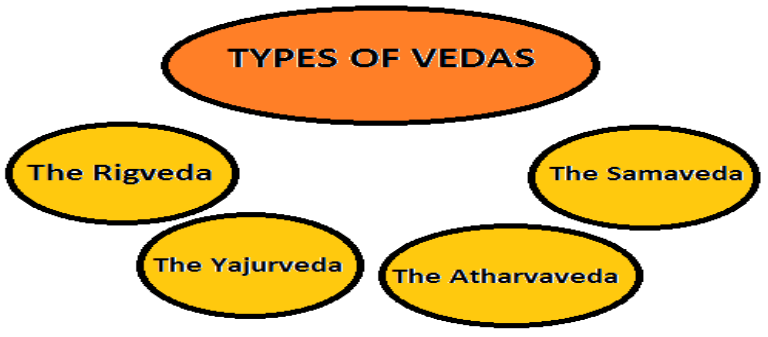

Figure 1. Types of Vedas

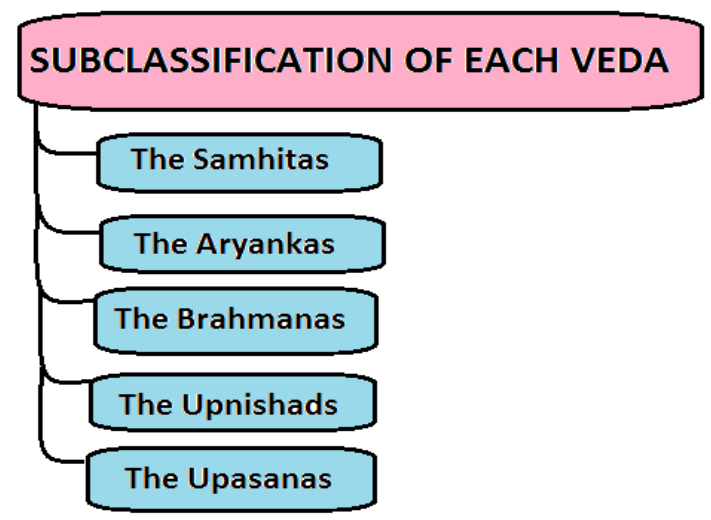

Figure 2: Each Veda has been sub classified into four major text type 


\section{International Journal of Research in Advent Technology, Vol.7, No.10, October 2019}

$$
\text { E-ISSN: 2321-9637 }
$$

Available online at www.ijrat.org

a. The Samhitas (Mantra's and benediction)

b. The Aryankas (Texts on rituals, ceremonies, sacrifices and symbolic sacrifices)

c. The Brahmanas (Commentaries on rituals ceremonies and sacrifices)

d. The Upnishads (Texts discussing meditation, philosophy and spiritual knowledge)

e. The Upasanas (Worship)

The vedic religion is totally explained in vedas and its voluminous vedic literature preserved into the modern times by the different priestly schools. The vedic religion texts are cerebral, orderly and intellectual. Vedic religion is now generally accepted to be a predecessor of Hinduism. Here the researcher will focus only on Upanishads [3].

\section{UPANISHADS}

The Upanishads reflects the last composed layers of the texts in the vedas. They are commonly referred to as 'Vedanta'. Etymologically, the name Upanishad is composed of the term upa (near) and shad (to sit) meaning something like "sitting down near". The principles of Upanishads are samsara, karma, dharma and moksha. These principles form metaphysical schemes which are shared by many Indian religions and philosophers.

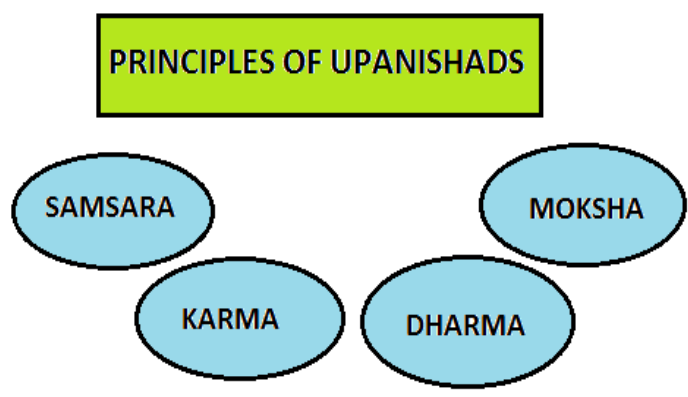

Figure 3: Basic principles of Upanishads

The concept of Samsara is reincarnation, the idea that after we die our soul will be reborn again in another body Another concept is Karma, which means "action", the idea that all actions have consequences, good or bad. Dharma means "duty", the idea of way of rightness. Dharma encouraged people of different social groups to perform their duties the best they could. Moksha means "liberation" or release from the reality. Seeking permanent peace or freedom from the sufferings seems impossible.

The "atman" is actually the core of our own self. The core of all creatures and their innermost essence is atman. It can only be perceived by meditation. The Upanishads are the foundation of Hindu philosophical thoughts and its diverse traditions[4].
Yoga came in practice from the methods of Upanishads. Yoga is a practice in science related to spiritual discipline, which focuses on the consonance of the body and mind. Practicing the art of yoga gives us a healthy living. The word 'Yoga' is derived from the sanskrit root 'yuj', meaning 'to join' or 'to yoke' or 'to unite' [5]. As per yogic scriptures, yogic practices results in the union of individual consciousness to the universal consciousness, therefore balancing a perfect harmony between the body and the mind. One who achieves this level of oneness of existence is said to be in yoga, and is termed as a 'yogi', having attained to a state of freedom referred to as mukti, nirvana or moksha. Thus the aim of yoga is self-realization, to overcome all kinds of sufferings leading to 'the state of liberation' (moksha) or 'freedom' (kaivalya)[5]. It is considered by many to be the oldest defined practice of self-development. Living with freedom in all walks of life, health and harmony shall be the main objectives of yoga practice [6]. In general practicing yoga leads to:

\section{A. IMPROVED FLEXIBILITY}

In yoga 'flexibility' is an attitude that invests and transforms the mind as well as body. The yoga postures for flexibility will help us lengthen and stretch your muscles in a safe, effective way. It helps the inner working of your body and focus on specific mechanisms that help you stretch.

\section{B. STRESS RELIEF}

Many popular techniques found to reduce stress derived from yoga such as controlled breathing, meditation, physical movements, mental imaginary and stretching[7].

\section{MENTAL FITNESS}

Yoga helps in balancing our mental health too. It helps us dealing in various problems like stress, anxiety, depression etc. The practices involved in mental fitness are meditation, asanas, and breathing.

\section{PHYSICAL FITNESS}

It improves flexibility and core strength that also leads to weight loss and reduces risk injury. Yoga postures help us in creating balance, strength and increased flexibility and relaxation in the body [8].

\section{E. SPIRITUAL GROWTH}

According to ancient yogic tradition, it teaches spiritual and the physical are interconnected and that one deeply affects the other. In yoga, the physical health and the spiritual health are both interconnected. Reconciling the body with the spirit is a main objective of yoga [9]. This is achieved by observing the eight limbs of yoga, which includes: 


\section{International Journal of Research in Advent Technology, Vol.7, No.10, October 2019 E-ISSN : 2321-9637 \\ Available online at www.ijrat.org}

a. Yama, which means social restraints or ethical values.

b. Niyama, is personal study.

c. Asanas or postures.

d. Pranayama, means breath work.

e. Pratyahara or sense withdrawal to prepare for meditation.

f. Dharana, means intense concentration.

g. Dhyana, means meditation.

h. Samadhi is spiritual enlightenment and bliss.

\section{ORIGIN OF VEDIC PSYCOLOGY}

Vedic psychology is drawn from the vedas, it uses practical techniques focusing on employing the intelligence (buddhi) for self-study and introspection. These techniques build self-awareness, so one can successfully manage the mind and emotions so they do not react in unconscious ways. Many people have studied and know about things, such as ego (ahankara) and past memories (samskaras) so they are academically knowledgeable [10]. They could easily pass a test on the parts of the mind. However, they may not have practical experience of being aware of and managing their own minds and emotions.

Without learning how to manage their mind, people continue to react in hurtful ways towards each other. Some people ignore and repress their emotions and struggle with lust, fear, greed, anxiety, jealousy, anger, addiction, and depression. Many people also meditate daily for years, but still suffer from emotional imbalances. Vedic psychology helps one to more clearly see how their mind is operating, so they can gain control of it, and ultimately become truly loving, understanding and accepting of everyone who crosses their path.

It explains the vedic perspective on the mind (manas), intellect (buddhi), ego (ahankara), and unconscious mind (chitta) and how they dynamically interact to create your thoughts, feelings and behaviours [10].

Vedic psychology helps in overcoming problems like anger, stress, conflicts, depression, anxiety, addiction, rejection, fear, overeating and other medical conditions such as blood pressure, sugar, heart and stomach problems and many more.

\section{TECHNOLOGY ADVANCEMENT}

The technology brought a large change over in a period as in a way to help people online. Therefore vedic psychology practices are done online with applications like Aura meditation, Headspace, Simple Habit, QuietKit, OMG. I can meditate Aware, Primed Mind, Flowing, Inscape, Paralign, PAUSE, StartMyDay, SwayMindfulness in motion and many more. People having problems nowadays have no need go to some specialist but they can solve these problems online, with the help of these online applications. Mostly these applications are free of cost. Through introspection and mindmanagement techniques, combined with supported group discussions, we will learn how we can deal with our problems skilfully, and become detached from them. The main skills that can be acquired with these applications are:

\section{A. PEACE}

Using your mind (Buddhi) to manage your everyday thoughts and feelings so that you can remain in a constant state of peace, despite the situation.

\section{B. TOLERANCE TRAINING}

Manage your ego (ahankara) to become more tolerant to different personality types. To manage ego, a healthy person uses defence mechanisms because we cannot balance out our ego. At our unconscious level defence mechanism helps ward off unpleasant feelings (i.e. anxiety) and make us feel better. Defence mechanisms is used as a tool to protect ourselves from feelings of anxiety or guilt, which arise because we feel threatened or because our ego becomes too demanding [11],[12]. Different defence mechanisms techniques that are used by us in our daily life include regression, repression, identification, sublimation and rationalization. Our ego satisfies our id and super ego.

\section{a. $\quad$ Id}

The id is the unconscious reservoir of the libido, the psychic energy that fuels instincts and psychic processes. It is a selfish, childish, pleasure-oriented part of the personality with no ability to delay gratification [12]

\section{b. Super Ego}

The superego contains internalised societal and parental standards of "good" and "bad", "right" and "wrong" behaviour. They include conscious appreciations of rules and regulations as well as those incorporated unconsciously [12]. It is based on moral principles.

\section{TENSION TRIGGERS}

Identifying and managing memories (samskaras) in the unconscious mind (chitta) that create tension, and drive negative thoughts, feelings and unhealthy behaviours.

Different types of mindfulness activities are not acquired at one place. So there is a need of distance education which is time consuming and requires some serious commitment of time. It is more difficult for people with busy schedules or physical limitations. The people around us during the session can also affect us, as a result there is no $100 \%$ effectiveness in the activities that are been 


\section{International Journal of Research in Advent Technology, Vol.7, No.10, October 2019 E-ISSN : 2321-9637 \\ Available online at www.ijrat.org}

practiced and these sessions are even expensive. Some people feel self-conscious doing the postures in yoga. Therefore as a solution to these problems the technical development in this field has brought a major change in lives. The applications give us different types of activities in a single platform that helps us in all aspects.

\section{HOW APPLICATIONS WORKS}

These applications make us feel our body relax, the weight of your arms and legs release so you're not left in the lurch with our own breath. They help us become more aware of how our mind (manas) works, how our feelings get generated and how to catch our feelings before they escalate and manifest in undesirable ways.

So the applications help by giving mindfulness by providing different types of features such as:

\section{A. MEDITATION}

It has different types of meditation practices, with timer system for every breathing practice. To take the guesswork out of choosing what kind of guided meditation suites you at any particular moment, many short guided meditations and acupressure videos, tuned to how you feel.

\section{B. SOUNDS OF NATURE}

The sounds of nature are in existence even before music was born; it has been deeply connected with the life activities and the process of human evolution. A research has been performed on effect of nature sounds on mental health where brain activity was measured in a MRI scanner and their autonomic nervous system activity was monitored via minute changes in heart rate. The brain connectivity reflected an outward directed focus of attention [13]. It helps to relax and bring positive attitude. The sounds of nature that are included in the mindfulness applications are sounds of waterfall, rain, wind and travelling waves.

\section{LIFE COACHING SESSIONS}

\section{a. Stress and anxiety}

Stress can be positive or negative, but in today's world the level of negative stress has increased so much. The ability to manage stress, anxiety and achieve healthy lifestyle varies with age. The highest stress level evaluated through a study is found in the age group of 18 to 33 years. Level of stress in this generation is very high because competition in every field of life is highly increased. Sessions on dealing with stress and anxiety are in so demand because every person is dealing with it and solutions are at most needed.

\section{b. Performance mindset}

It helps us to know our potential and to believe we can do more. Also it helps us to get us back in track as due to some reasons our believe in our-self sometimes lacks. The sessions are motivational which helps us change our current perspective and mindset.

\section{c. Personal growth}

Personal growth is a continious process of understanding and developing oneself in order to achieve our maximum potential. Personal development is an important part in a person's growth, maturity, success and happiness. It is the foundation of emotional, physical, intellectual, and spiritual health [14]. It refers to self-improvement in a period of time. There are many factors in personal growth that these sessions help us to upgrade within us.

\section{d. Work and productivity}

It simply means 'Do more with less'. The goal is to increases productivity at work with time. The sessions teach us about different techniques like to divide our tasks, prioritizing the most important task first, no usage of mobile phones, organizing the work environment, listening to calming sounds etc.

\section{e. Parenting and kids}

These sessions are specified for parents or parent to be. We know being a parent can be both rewarding and challenging. They deliver lectures on positive parenting, creating a safe, interesting environment, usage of assertive discipline and much more. These sessions are here to support and help us building a strong and secure relationship with our child.

\section{f. Life challenges}

No one have a perfect life. We have to overcome the challenges to make it perfect. These sessions help us develop a new skill, capitalize our strength, overcome weakness, expand our comfort zone, improve our thinking, clarifying our goals and priority and many more.

\section{g. Creativity}

Creativity is dependent on individual. It leads individual to use their imagination to think about existing factors with the aim of finding innovative solutions [15]. Creative people use more percentage of their brain on an average and will have a positive attitude. Creativity can be increased by doing meditations and different asanas.

\section{THERAPY AND JOURNAL}

Music therapy and motivational journal keeps us focused and motivated. Music therapy is a process in which music help the individual to improve, restore or maintain mental health. This therapy helps in depression, infant 


\section{International Journal of Research in Advent Technology, Vol.7, No.10, October 2019 E-ISSN : 2321-9637 \\ Available online at www.ijrat.org}

development, sleep quality and many more. It balances out the hormones in our body according to the situation.

\section{E. MOOD SELECTION}

The applications ask for our physical and mental health. Firstly they ask about our physical condition like if it is excellent, good, not good or bad. Then they ask about our emotions in the current situation like if we are feeling anxiety, sadness, happy, depressed etc.

\section{F. WAKING AND SLEEPING TIME}

This feature helps us to set a lifestyle about prioritizing our task. Selecting our waking and sleeping timing gives us a routine, which could be followed as a habit. According to the waking and sleeping timing the specified session starts.

\section{G. COURSES}

Many different types of courses are available, which are likely free of cost and are delivered by renowned coaches. Themed audio tracks such as, "Relax, Ground, and Clear" or "Gratitude." and many more are available. Sessions vary in length, lasting between 2 to 15 minutes. These applications prompt us with physical, mental, and emotional check-ins before curating a selection of particular meditation. The sessions are easy to follow each day to help you really get good at your practice.

\section{H. YOGA}

Different types of applications have distinct features like yoga instructor with detailed voice and visual instructions that guide through each pose and every breath.

\section{TRACKER}

They track our progress which also keeps us motivated and help us build a habit easily as we can choose the time duration that suits us as a remainder on a daily basis.

\section{CONCLUSION}

Human intellect is not an adequate tool to understand the immense complexity of reality. Our mind is constantly bombarded with sensations from inside and outside. Mind struggles to remain in balance. An easier and efficient solution is to bring a change within oneself. Technology has ruled over within the past years and has brought anywhere solution to our major concern with our physical and mental issues. The applications for meditation and mindfulness have a unique approach that allows you to check in with our emotions, and then recommends us with different solutions.

\section{REFERENCES}

[1] S.Dasa. (n.d.). About Vedic Psychology.JIVA.[Online]. Available: https://www.jiva.org/psychology/about-vedic-psychology/

[2] J.Lochtefeld \& Brahman, "The Illustrated Encyclopedia of Hinduism", Rosen Publishing, 1-122.

[3] P.Stephen, "Yoga, Karma and Rebirth: A Brief History and Philosophy”, Columbia University Press, 28-30 (2009).

[4] S.Radhakrishnan and C.A. Moore, "A Sourcebook in Indian Philosophy”, Princeton, 453 (1967).

[5] E.Bryant, "The Yoga Sutras of Patanjali". Rutgers University, (2011).

[6] S.Dasa. (June 2016). Vedic Psychology: From Managing To Understanding the Mind. JIVA.[Online]. Available: http://ayurveda.jiva.com/jiva/courses/train-with-us/635.html

[7] Yoga Journal. [Online]. Available: www.yogajornal.com

[8] V.Adams.(n.d.).The benefits of yoga for physical fitness. Do you yoga.[Online].Available:https://www.doyouyoga.com/thebenefits-of-yoga-for-physical-fitness-36232/

[9] How yoga aids in spiritual development.Yoga.org.nz. [Online]. Available:http://yoga.org.nz/blog/2011/how-yoga-aids-inspiritual-development/

[10] D.Wendy, "Textual Sources for the Study of Hinduism", 1st Edition, University of Chicago Press, 2-3(1990).

[11] A.Freud, "The Ego and the mechanisms of defense", Institute of Psycho-Analysis, London: Hogarth Press (1937).

[12] R.Plutchik., H Kellerman, and H. R. Conte, "A structural theory of ego defences and emotions" In C. E. Izard (Ed.), Emotions in personality and psychopathology New York: Plenum Press, (pp. 229--257) (1979).

[13] D.Cassandra Gould van Praag, N. Sarah Garfinkel, Oliver Sparasci, Alex Mees, O Andrew Philippides, Mark Ware, Cristina Ottaviani and D. Hugo Critchley, "Mind-wandering and alterations to default mode network connectivity when listening to naturalistic versus artificial sounds", Scientific Reports; 7: 45273 DOI: $10.1038 /$ srep45273.

[14] Why is personal growth so important? World Minded.[Online]. Available:http://worldminded.com/why-is-personal-growth-soimortant/

[15] C.M. Ford, "A theory of individual creative action in multiple social domains", Academy of management review; 21, 4, 1112,(1996).

\section{AUTHORS PROFILE:}

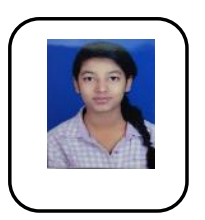

Vani Nayal is pursuing B.Tech, (ECE) is a student of $5^{\text {th }}$ semester in Birla Institute of Applied Sciences, Bhimtal, Nainital, Uttarakhand. She has also published a research paper entitled "Social Engineering: A Psychological need" in a reputed international journal. Her areas of interests are Social Psychology and Data analytics.

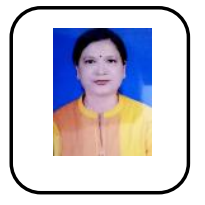

Dr. Madhu Lata Nayal is Professor and Head in Department of Psychology, Kumaun University, SSJ Campus, Almora, Uttarakhand. Her research interest includes Clinical and Developmental psychology with more than 30 research papers published in reputed national and international journals .Till now,10 research scholars have completed their $\mathrm{PhD}$. degree under her supervision. 